\title{
Preferential Syntheses of Semiconducting Vertically Aligned Single-Walled Carbon Nanotubes for Direct Use in FETs
}

\author{
Liangti Qu, Feng Du, and Liming Dai* \\ Department of Chemical and Materials Engineering, School of Engineering, \\ University of Dayton, 300 College Park, Dayton, Ohio 45469
}

Received April 4, 2008; Revised Manuscript Received June 8, 2008

\begin{abstract}
We have combined fast heating with plasma enhanced chemical vapor deposition (PECVD) for preferential growth of semiconducting vertically aligned single-walled carbon nanotubes (VA-SWNTs). Raman spectroscopic estimation indicated a high yield of up to $96 \%$ semiconducting SWNTs in the VA-SWNT array. The as-synthesized semiconducting SWNTs can be used directly for fabricating FET devices without the need for any postsynthesis purification or separation.
\end{abstract}

Carbon nanotubes can be conceptually viewed as a graphene sheet rolled up into a nanoscale tube form to produce the single-walled carbon nanotubes (SWNTs). ${ }^{1}$ There may be additional graphene tubes around the core of a SWNT to form multiwalled carbon nanotubes (MWNTs). ${ }^{1}$ Depending on their diameter and helicity of the arrangement of carbon atoms in the nanotube walls, SWNTs can exhibit semiconducting or metallic behavior. ${ }^{1}$ Semiconducting SWNTs have been demonstrated to be very promising building blocks for constructing various electronic devices for a large variety of applications, ranging from chemical/biosensors to molecular electronics. ${ }^{2-6}$ For many of these applications, field effect transistors (FETs) made from SWNTs often play an important role.

One of the major hurdles for the widespread application of SWNTs in semiconductor electronics is the coexisting of metallic and semiconducting carbon nanotubes in the assynthesized samples. Due to the presence of metallic tubes, FET characteristics (e.g., the on/off ratio and integration uniformity) become poor and uncontrollable. For instance, the on/off ratio is usually less than 10 for FETs based on nonseparated carbon nanotube network films, which is actually too small for any practical application. ${ }^{7}$ Therefore, it is critical to separate metallic nanotubes from semiconducting SWNTs for constructing nanotube-based semiconductor devices of high performance. A few separation approaches, including electrophoresis, ${ }^{8,9}$ tube-type-specific physicochemical modification, ${ }^{10}$ and selective elimination of metallic SWNTs by electrical breakdown, ${ }^{11,12}$ laser irradia-

* Corresponding author. E-mail: 1dai@udayton.edu. tion ${ }^{13}$ and gas-phase plasma etching,${ }^{14}$ have been devised. However, the problem associated with the coexisting metallic nanotubes has not yet been completely solved as the postsynthesis separation processes are often tedious and even involve possible contamination or degradation of nanotubes. ${ }^{1,15}$ It will be a significant advancement for the development of electronic devices from carbon nanotubes if we can preferentially synthesize semiconducting SWNTs for direct use in FETs. Indeed, chemical vapor deposition (CVD) methods with and without the plasma enhancement have been used for preferentially produce nonaligned SWNTs with a high percentage of semiconducting nanotubes $(\sim 90 \%)^{16}$ or SWNTs with a specific chirality distribution. ${ }^{17-21}$ Due to the random feature of nonaligned SWNTs, it is difficult to further increase the percentage of semiconducting nanotubes necessary for the high-throughput construction of electronic devices. Although the mechanism for preferentially growing the semiconducting SWNTs is still not well understood, these pioneering studies indicate the possibility for selective syntheses of semiconducting SWNTs by carefully controlling the growth parameters.

On the other hand, it is highly desirable to grow aligned/ micropatterned SWNTs for electronic applications as their structure-property can be readily assessed while they can be effectively incorporated into devices. ${ }^{1}$ The vertically aligned structure will not only provide a well-defined large surface area for the device performance enhancement but also allow controlled functionalization of nanotubes along the tube length for incorporating multifunctionalities. ${ }^{22,23}$ Although the growth of aligned/micropatterned MWNTs has 


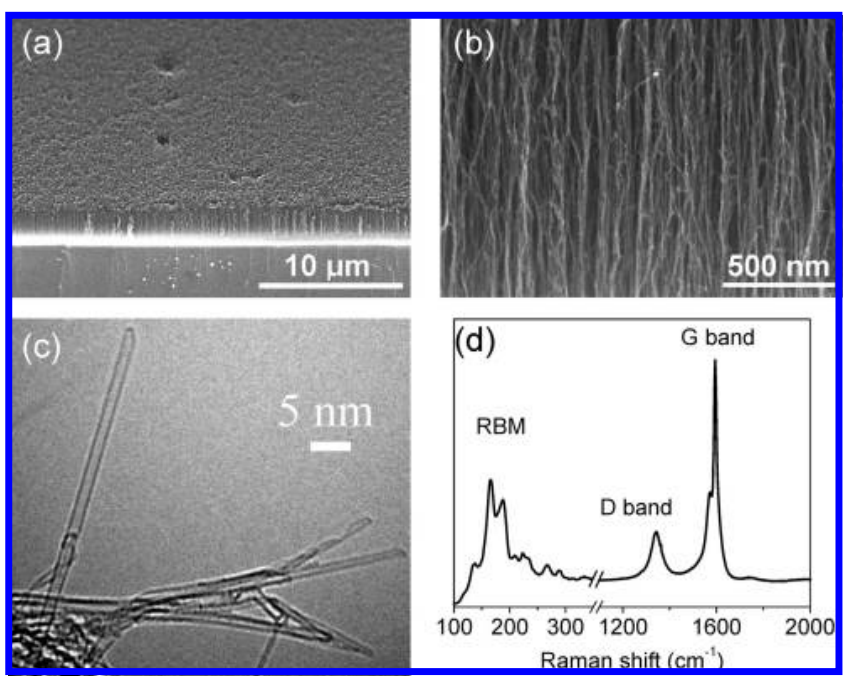

Figure 1. (a, b) SEM, (c) TEM images, and (d) Raman spectrum of the as-grown SWNTs.

been known for some years, ${ }^{24}$ the synthesis of aligned SWNT forests is a recent development. ${ }^{25}$ Along with others, ${ }^{25 \mathrm{e}}$ we have used the combined PECVD and fast heating method to grow VA-SWNTs on a large scale, ${ }^{26}$ and to produce multicomponent micropatterns of VA-SWNTs interposted with VA-MWNTs. ${ }^{27}$ As far as we are aware, the selective growth of semiconducting VA-SWNTs has not been reported, which, if realized, should facilitate the development of various nanotube electronic devices. Here, we report our recent work on the preferential growth of semiconducting VA-SWNTs by using the combined PECVD and fast heating method with necessary modifications under a low pressure (30 mTorr) $\mathrm{C}_{2} \mathrm{H}_{2}$ flow as carbon source without additional carrier gas. As we shall see later, the resultant semiconducting VA-SWNTs can be directly used as the electronically active materials in FET devices even without any purification or separation.

In a typical experiment for the synthesis of semiconducting VA-SWNT arrays, a thin film of Fe $(0.5 \mathrm{~nm})$ was sputtercoated on a $10 \mathrm{~nm}$ thick $\mathrm{Al}$ layer precoated on the $\mathrm{SiO}_{2}$ surface of a $\mathrm{SiO}_{2} / \mathrm{Si}$ wafer. The $\mathrm{Al}$ coating was used to effectively prevent $\mathrm{Fe}$ catalyst nanoparticles from aggregation at the high temperature required for the growth of VASWNTs. To start the nanotube growth process, the catalystcoated $\mathrm{SiO}_{2} / \mathrm{Si}$ wafer was quickly $(<5 \mathrm{~s})$ moved from a cool zone $\left(25^{\circ} \mathrm{C}\right)$ into the center of a plasma-enhanced $(80 \mathrm{~W}$, $13.56 \mathrm{MHz}$ ) tube furnace heated at $750{ }^{\circ} \mathrm{C}$ under a pure gas flow of $\mathrm{C}_{2} \mathrm{H}_{2}$ (atomic absorption grade, $99.8 \%$, Airgas Great Lakes. Inc.) at a low pressure of 30 mTorr. Three minutes later, the nanotube deposited $\mathrm{SiO}_{2} / \mathrm{Si}$ wafer was taken out from the furnace for subsequent analyses without any purification.

Figures $1 \mathrm{a}$ and $1 \mathrm{~b}$ reproduce scanning electron microscopic (Hitachi S-4800 high-resolution SEM) images, showing a homogeneous coverage of about $2-3 \mu \mathrm{m}$ long well-aligned nanotubes over the whole substrate surface. A transmission electron microscopic (Hitachi H-7600 TEM unit) image for the constituent nanotubes taken from an ethanol dispersion of the VA-SWNT sample is given in Figure 1c, which reveals

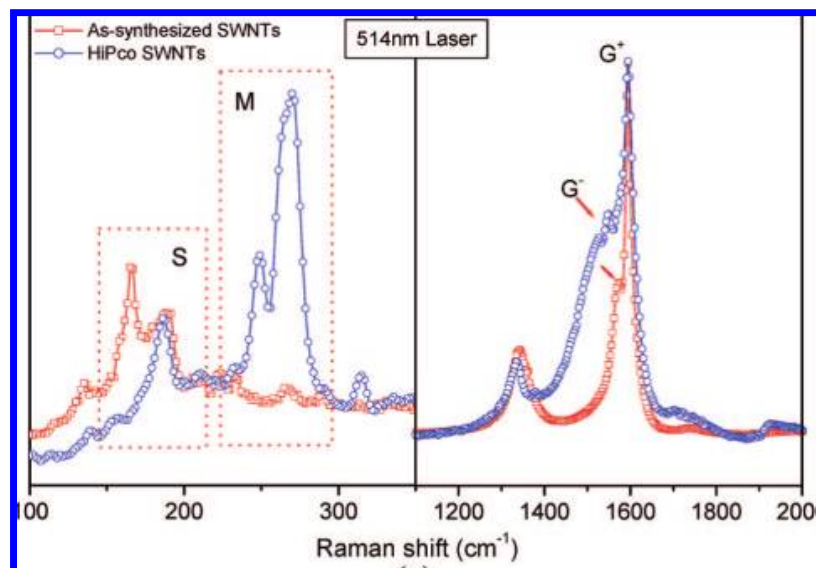

(a)

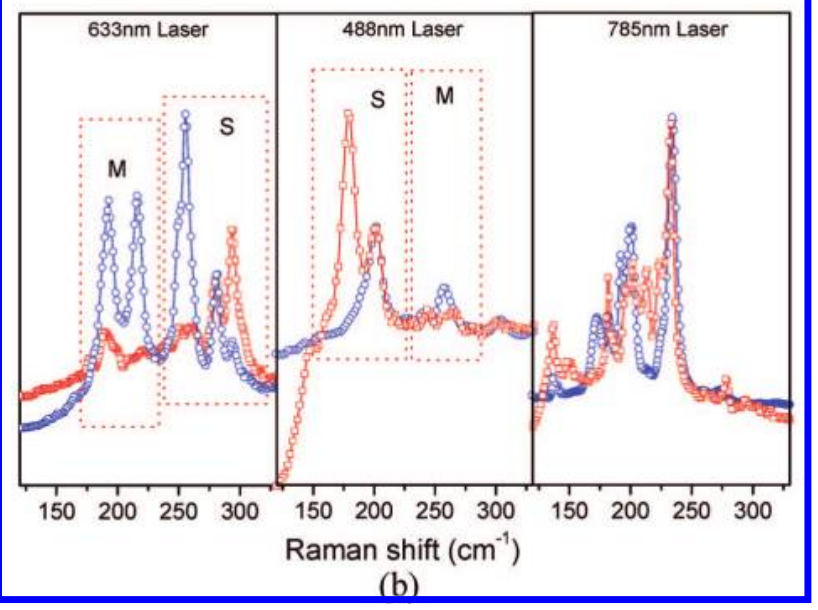

Figure 2. Typical Raman spectra of the as-synthesized ( $-\square-$ ) and HiPco SWNTs (-O-) using the excitation laser wavelengths of $488,514,633,785 \mathrm{~nm}$ (peaks within the rectangles marked with $\mathrm{S}$ and $\mathrm{M}$ correspond to the semiconducting and metallic SWNTs, respectively).

SWNT characteristics for each of the individual nanotubes (Figure 1c). Atomic force microscopic (AFM) analyses show apparent diameters in the range of $0.8-2 \mathrm{~nm}$ for the assynthesized SWNTs (see Figure S1, Supporting Information). The corresponding Raman spectrum (inVia micro-Raman spectrometer, Renishaw) recorded with a $514 \mathrm{~nm}$ laser for the nanotube sample shown in Figure 1a clearly shows the radial breathing mode (RBM) for SWNTs (Figure 1d), from which the nanotube diameters were found to be in a good consistence with those measured by AFM. ${ }^{28}$

The RBM of Raman spectra can be used to assign and quantitatively evaluate metallic and semiconducting nanotubes. ${ }^{8,9,10 a-f, 13,28}$ To confirm the semiconducting properties of the as-synthesized VA-SWNTs, we systematically measured Raman spectra with laser beams of different excitation wavelengths. Commercial HiPco SWNTs with a known metallic-to-semiconducting ratio (ca. 40\%:60\%) were used as reference. ${ }^{10 c, 16 a}$ Figure 2a shows the spectroscopic details over the RBM and G-band regions recorded with the $514 \mathrm{~nm}$ laser $(2.41 \mathrm{eV})$ for the as-synthesized VA-SWNTs and HiPco SWNTs to give a qualitative indication of the relative population of semiconducting to metallic nanotubes in these samples. ${ }^{10 \mathrm{c}}$ As expected, the HiPco SWNTs show 


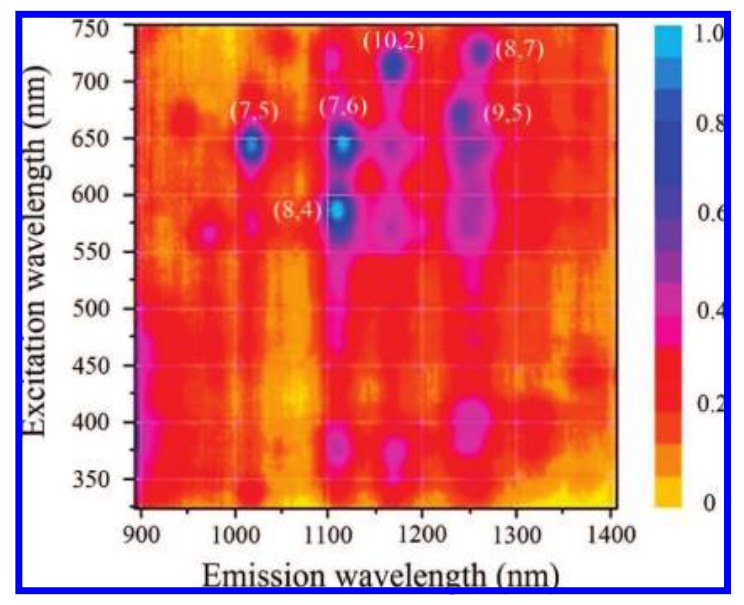

Figure 3. Photoluminescence excitation/emission contour plots of the as-synthesized SWNTs.

typical RBM features for semiconducting nanotubes over ca.150-210 $\mathrm{cm}^{-1}$ and metallic nanotubes in the region between about 210 and $280 \mathrm{~cm}^{-1}$, along with a strong and broad Breit-Wigner-Fano (BWF) line shape for the Gband associated with metallic nanotubes (curves with circular dots in Figure 2a). ${ }^{8}, 10 \mathrm{a}, \mathrm{c}, \mathrm{g}, \mathrm{f}, 29$ In contrast, the corresponding Raman spectrum of the as-synthesized VA-SWNTs (curves with squares in Figure 2a) is dominated by spectroscopic features of semiconducting SWNTs in both the RBM and G-band regions, indicating the presence of a high percentage of semiconducting nanotubes. Further evidence for the high percentage of semiconducting nanotubes in the as-grown VASWNT sample comes from the corresponding Raman spectra measured with a 633,488 , and $785 \mathrm{~nm}$ wavelength laser, respectively. As seen in Figure 2b, the RBM modes of the as-grown VA-SWNTs recorded with 633 and $488 \mathrm{~nm}$ lasers reveal dominant features for semiconducting nanotubes (curves with squares in Figure 2b) while the corresponding spectra for HiPco SWNTs (curves with circles in Figure 2b) indicate the coexistence of semiconducting and metallic nanotubes. The above observed difference is consistent with Figure 2a. However, the RBM modes recorded with a 785 $\mathrm{nm}$ laser show extensive signals of semiconducting nanotubes for both the as-synthesized VA-SWNTs and HiPco sample as only semiconducting nanotubes are Raman active at this particular excitation wavelength. ${ }^{10 \mathrm{c}}$

Although it is not easy to precisely measure the percentage of semiconducting nanotubes in the as-grown SWNT array, we can make a reasonable estimation from the integrated Raman peak intensities by using the commercial HiPco SWNTs as reference. ${ }^{10 \mathrm{c}, \mathrm{f}, 28 \mathrm{c}}$ In view of the known ratio of 40\%:60\% for metallic-to-semiconducting nanotubes in the commercial HiPco sample, ${ }^{10 c, 16 a}$ we estimated about $96 \%$ of semiconducting nanotubes in the as-grown VA-SWNT array by comparing its integrated RBM intensity with that of HiPco SWNTs (Figure 2a). Similar calculations using the RBMs shown in Figure 2b recorded with 633 and $488 \mathrm{~nm}$ lasers also indicate more than $80 \%$ of semiconducting nanotubes in the as-grown VA-SWNT sample, though RBMs associated with the $514 \mathrm{~nm}$ laser have been demonstrated to provide the most accurate ratios of the metallic to semiconducting nanotubes in samples enriched with semiconducting nanotubes. ${ }^{10 \mathrm{c}}$ Photoluminescence excitation/emission contour plots of the as-synthesized SWNTs measured by simply dispersing them in $\mathrm{D}_{2} \mathrm{O}$ with sodium dodecylbenzene sulfonate (SDBS) without any separation revealed the presence of mainly $(7,5),(7,6),(8,4),(8,7),(9,5)$ and $(10,2)$ semiconducting SWNTs (Figure 3). ${ }^{30}$

It was demonstrated that the plasma enhancement played an important role in the selective growth of semiconducting VA-SWNTs, as is the case for growing their nonaligned counterparts. ${ }^{16}$ To ensure stable growth conditions for the preferential formation of semiconducting SWNTs, we have

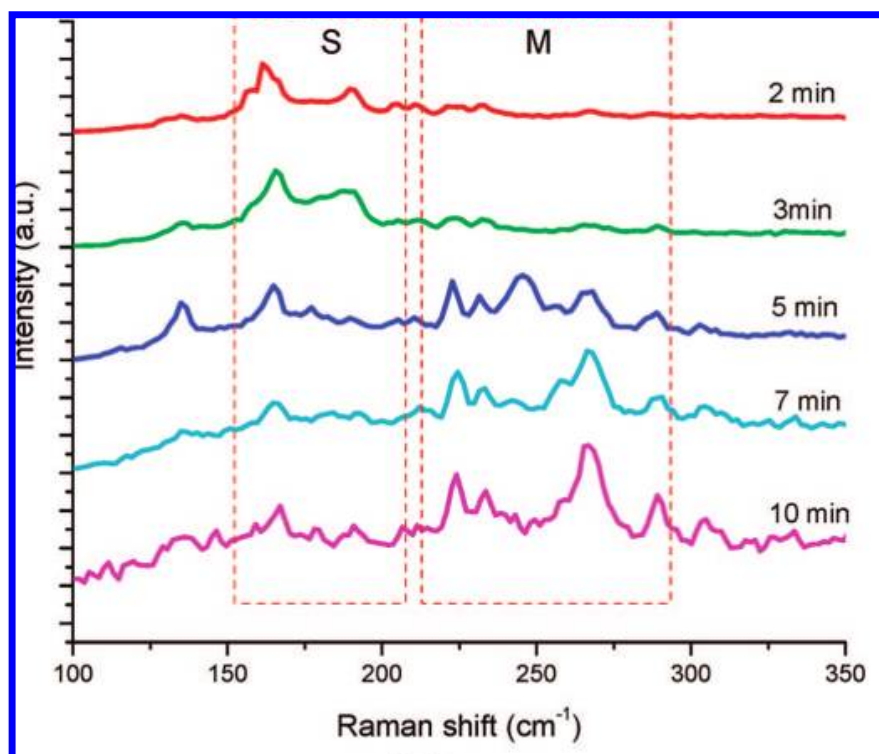

(a)



(b)

Figure 4. The influence of the (a) growth time $\left(750{ }^{\circ} \mathrm{C}\right)$ and $(\mathrm{b})$ temperature $(3 \mathrm{~min})$ for the selective growth of semiconducting VASWNTs (514 nm laser). 


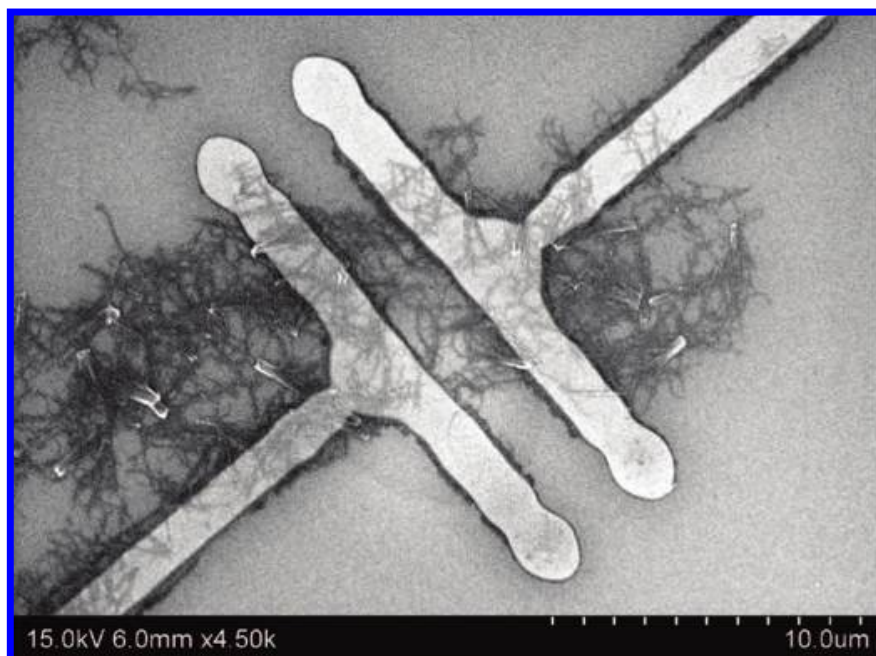

(a)

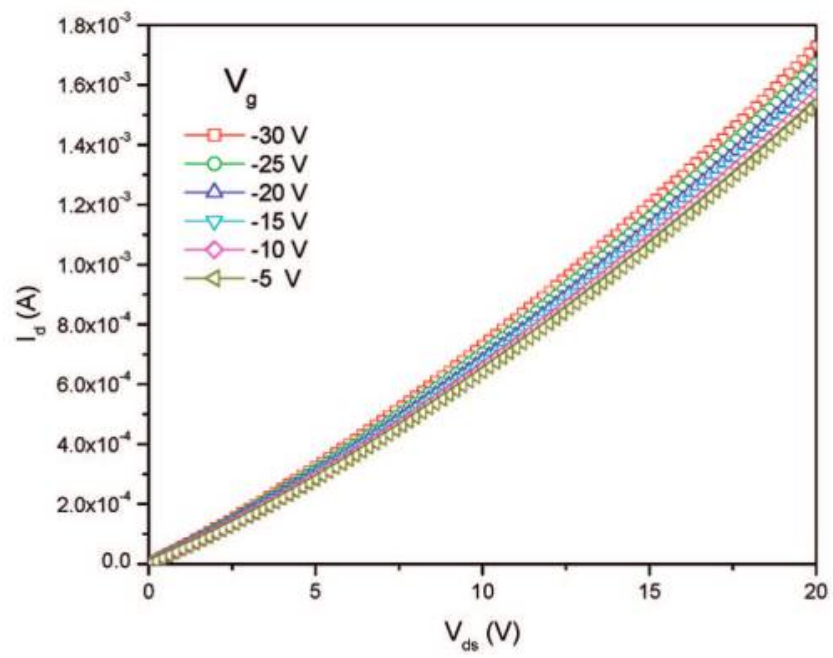

(c)

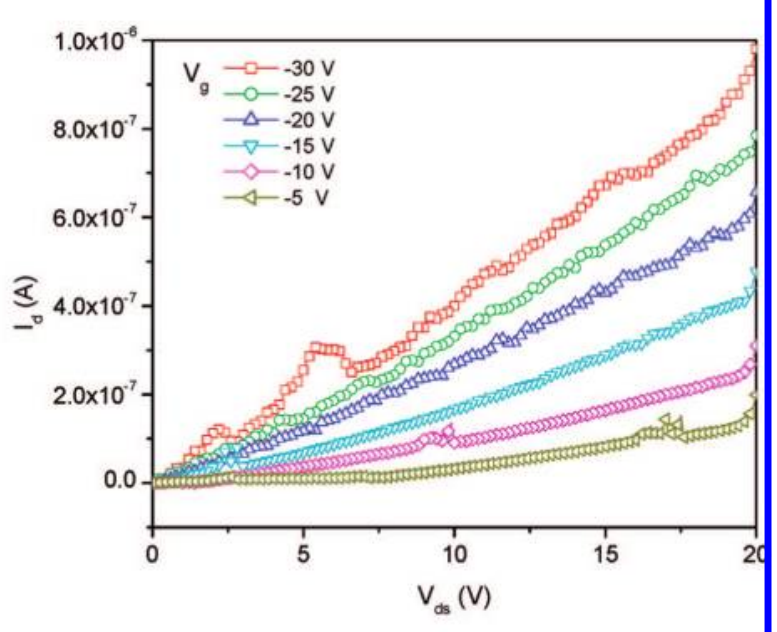

(b)

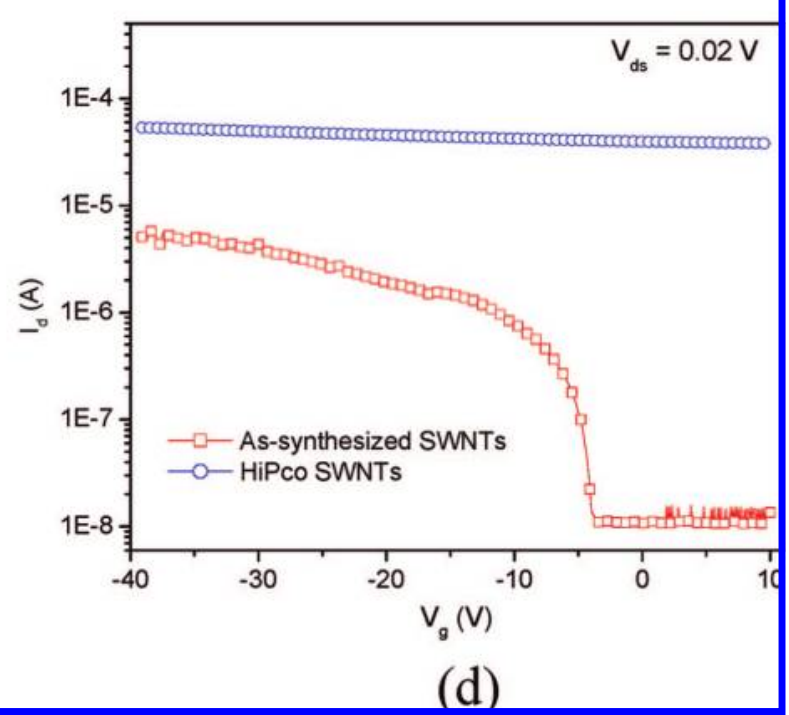

Figure 5. (a) A typical SEM image of the as-synthesized SWNT bundle network on two electrodes. Drain current vs drain voltage measured at gate voltages ranging from -30 to $-5 \mathrm{~V}$ in $5 \mathrm{~V}$ steps for (b) the as-synthesized SWNT FET and (c) HiPco network device; and (d) drain current vs gate voltage for both the as-synthesized SWNT (- $\square-$ ) and HiPco ( $\left.-\mathrm{O}^{-}\right)$network devices measured at a drain voltage of 0.02 V.

used $\mathrm{C}_{2} \mathrm{H}_{2}$ only, without any carrier gas. This, together with the fast heating, could minimize any possible disturbance to the growing nanotubes, which otherwise may introduce defect(s) into the nanotube structure. Furthermore, we found that a well-controlled low gas pressure $\left(30\right.$ mTorr of $\left.\mathrm{C}_{2} \mathrm{H}_{2}\right)$ is critical for the selective growth of semiconducting nanotubes as an increased gas flow rate often facilitates the growth of metallic nanotubes. Besides, the growth of semiconducting nanotubes was found to also depend strongly on the growth temperature and time. As seen in Figure 4, Raman peak intensities corresponding to metallic nanotubes with respect to those of semiconducting nanotubes increased with increasing temperature and growth time. Although these results indicate a narrow growth window for the preferential formation of semiconducting nanotubes, VA-SWNT arrays with more than $95 \%$ semiconducting nanotubes have been repeatedly synthesized by carefully controlling the growth parameters (e.g., gas flow rate, temperature, time).
The high yield of semiconducting SWNTs produced by the preferential synthesis described above promoted us to directly use the as-synthesized SWNTs for constructing nanotube FETs without any postsynthesis purification or separation, which is necessary for the use of other nanotube samples in FETs. ${ }^{11 c, 31}$ Specifically, we dispersed $0.1 \mathrm{mg}$ of the as-synthesized VA-SWNTs in $1 \mathrm{~mL}$ of DMF under ultrasonication (Bransonic, 2510R-MT, $100 \mathrm{~W}$ ) for $10 \mathrm{~min}$, followed by solution-casting the slightly dispersed nanotube bundles between the drain and source Au electrodes prefabricated on a $\mathrm{SiO}_{2} / \mathrm{Si}$ wafer $\left(400 \mathrm{~nm}\right.$ thick $\left.\mathrm{SiO}_{2}\right)$ to form a nanotube bundle network FET with the Si substrate to act as the gate electrode (Figure 5a). For comparison, we have also prepared a network FET based on HiPco SWNTs according to the same procedure. We deliberately chose bundled nanotubes instead of individual nanotubes for the FET investigation in order to demonstrate the high percentage 
of semiconducting nanotubes in the as-grown VA-SWNT sample.

As can be seen in Figure 5b, FETs based on the as-synthesized SWNTs showed a typical field effect characteristic with the drain current increased with increasing negative gate voltage, indicating a p-type semiconductor for the SWNTs. In contrast, Figure 5c shows almost no field effect for the corresponding HiPco device. The variations of drain current with the gate voltage for a drain voltage of $0.02 \mathrm{~V}$ given in Figure $5 \mathrm{~d}$ show an on/off ratio of more than 100 for the as-synthesized SWNT FET in air and a quasilinear plot with a relatively small slope for the HiPco device. The on/off ratio of more than 100 for the as-synthesized SWNT network FET is comparable to that of planar FETs consisting of parallel SWNTs after electrical breakdown of metallic nanotubes. ${ }^{11 \mathrm{~b}}$ Since the source-drain channel width for our FETs (Figure 5a) is close to the nanotube length of ca. 2-3 $\mu \mathrm{m}$ (Figure 1a), the long channel effect $\mathrm{t}^{32}$ associated with high on/off ratios previously observed for short nanotubes dispersed over long channel devices seems to be insignificant in the present study. Due also to the similar length scale between the nanotube length and channel width, the low percentage of metallic nanotubes randomly dispersed in the semiconducting SWNT matrix could be insufficient for the formation of a continuous network across the source and drain electrodes to cause any noticeable effect on the FET performance. Once again, the above results clearly indicate the high yield of semiconducting nanotubes in the as-synthesized VA-SWNT sample. The mobility $(\mu)$ of the as-synthesized SWNTs was estimated, according to the standard formula, ${ }^{11 \mathrm{c}}$ to be $c a .11 .4 \mathrm{~cm}^{2} \mathrm{~V}^{-1} \mathrm{~s}^{-1}$ in air, which is slightly higher than that of a planar FET after electrical breakdown of metallic nanotubes. ${ }^{11 \mathrm{~d}}$

We have investigated more than 10 such FET devices based on the as-synthesized SWNTs and found the overall on/off ratio to be around $10^{2}$ and mobility to be 4.2 to 13 $\mathrm{cm}^{2} \mathrm{~V}^{-1} \mathrm{~s}^{-1}$ (cf. Figure S2, Supporting Information). The relatively high mobility observed above indicates that the bundled semiconducting SWNT network could transport electrons efficiently. Besides, a FET device based on the assynthesized VA-SWNT array with the source and drain electrodes directly deposited onto the top surface of the VASWNTs supported by a $\mathrm{SiO}_{2} / \mathrm{Si}$ wafer $\left(400 \mathrm{~nm}\right.$ thick $\mathrm{SiO}_{2}$ with the Si substrate acting as the gate electrode) has also been constructed (see the inset of Figure S3, Supporting Information). Our preliminary results indicate that the vertically constructed FET from the as-synthesized VASWNT array also shows a reasonably strong field effect, though it has yet been optimized (Figure S3).

In conclusion, we have demonstrated the first preferential synthesis of vertically aligned SWNTs with the percentage content of semiconducting nanotubes up to $c a$. $96 \%$ by using the combined plasma-enhanced CVD and fast heating method for pyrolysis of pure $\mathrm{C}_{2} \mathrm{H}_{2}$ under a low pressure ( $\sim 30$ mTorr). The high yield of the resultant semiconducting SWNTs was confirmed by systematic Raman spectroscopic measurements. Photoluminescence excitation/emission spectroscopic measurements revealed the presence of mainly $(7,5),(7,6),(8,4)$,
$(8,7)$, $(9,5)$ and $(10,2)$ semiconducting SWNTs. The assynthesized semiconducting SWNT arrays can be used directly for fabricating either vertically constructed or horizontally deposited nanotube network FET devices without any purification or separation. The nanotube network FETs showed a very good device performance, comparable to that of SWNT thin film FETs after electrical breakdown of metallic nanotubes. Therefore, these selectively grown semiconducting VA-SWNT arrays should be attractive for the development of various optoelectronic nanodevices with high performance.

Acknowledgment. We gratefully acknowledge the financial support from AFOSR (FA9550-06-1-0384) and NSF (NIRT-0609077). Thanks also to the NEST Laboratory at UD for the access of SEM and TEM facilities.

Supporting Information Available: Experimental details, an AFM image of the as-synthesized semiconducting SWNTs and the corresponding topographic height analysis, and plots of drain current $v s$ gate voltage for the as-synthesized SWNT network and array. This material is available free of charge via the Internet at http://pubs.acs.org.

\section{References}

(1) Dai, L., Ed. Carbon Nanotechnology: Recent Developments in Chemistry, Physics, Materials Science and Device Applications; Elsevier: Amsterdam, 2006.

(2) (a) Tans, S.; Verschueren, A.; Dekker, C. Nature 1998, 393, 49. (b) Javey, A.; Guo, J.; Wang, Q.; Lundstrom, M.; Dai, H. Nature 2003, 424, 654. (c) Kong, J.; Franklin, N. R.; Zhou, C.; Chapline, M. G.; Peng, S.; Cho, K.-j.; Dai, H. Science 2000, 287, 622. (d) Zhong, Z. H.; Wang, D. L.; Cui, Y.; Bockrath, M. W.; Lieber, C. M. Science 2003, 302, 1377.

(3) Li, S.; Yu, Z.; Yen, S.-F.; Tang, W. C.; Burke, P. J. Nano Lett. 2004, 4, 753 .

(4) Bachtold, A.; Hadley, P.; Nakanishi, T.; Dekker, C. Science 2001, 294, 1317.

(5) Derycke, V.; Martel, R.; Appenzeller, J. Avouris, Ph. Nano Lett. 2001, $1,453$.

(6) Javey, A.; Wang, Q.; Ural, A.; Li, Y.; Dai, H. Nano Lett. 2002, 2, 929.

(7) See, for example: Japanese patent application P2005-45188.

(8) Krupke, R.; Hennrich, F.; von Lohneysen, H.; Kappes, M. M. Science 2003, 301, 344.

(9) Kim, W. J.; Usrey, M. L.; Strano, M. S. Chem. Mater. 2007, 19, 1571.

(10) (a) Chattopadhyay, D.; Galeska, L.; Papadimitrakopoulos, F. J. Am. Chem. Soc. 2003, 125, 3370. (b) Kim, S. N.; Luo, Z. T.; Papadimitrakopoulos, F. Nano Lett. 2005, 5, 2500. (c) Zheng, M.; Jagota, A.; Strano, M. S.; Santos, A. P.; Barone, P.; Grace Chou, S.; Diner, B. A.; Dresselhaus, M. S.; Mclean, R. S.; Bibiana Onoa, G.; Samsonidze, G. G.; Semke, E. D.; Usrey, M.; Walls, D. J. Science 2003, 302, 1545. (d) An, K. H.; Park, J. S.; Yang, C.-M.; Jeong, S. Y.; Lim, S. C.; Kang, C.; Son, J.-H.; Jeong, M. S.; Lee, Y. H. J. Am. Chem. Soc. 2005, 127, 5196. (e) Maeda, Y.; Kimura, S. I.; Kanda, M.; Hirashima, Y.; Hasegawa, T.; Wakahara, T.; Lian, Y.; Nakahodo, T.; Tsuchiya, T.; Akasaka, T.; Lu, J.; Zhang, X.; Gao, Y.; Yu, Y.; Nagase, S.; Kazaoui, S.; Minami, N.; Shimizu, T.; Tokumoto, H.; Saito, R. J. Am. Chem. Soc. 2005, 127, 10287. (f) Maeda, Y.; Kanda, M.; Hashimoto, M.; Hasegawa, T.; Kimura, S.; Lian, Y. F.; Wakahara, T.; Akasaka, T.; Kazaoui, S.; Minami, N.; Okazaki, T.; Hayamizu, Y.; Hata, K.; Lu, J.; Nagase, S. J. Am. Chem. Soc. 2006, 128, 12239. (g) Banerjee, S.; Wong, S. S. Nano Lett. 2004, 8, 1445. (h) Yang, C. M.; Park, J. S.; An, K. H.; Lim, S. C.; Seo, K.; Kim, B.; Park, K. A.; Han, S.; Park, C. Y.; Lee, Y. H. J. Phvs. Chem. B 2005, 109, 19242. (i) Banerjee, S.; Wong, S. S. J. Am. Chem. Soc. 2004, 126, 2073. (j) Strano, M. S.; Dyke, C. A.; Usrey, M. L.; Barone, P. W.; Allen, M. J.; Shan, H.; Kittrell, C.; Hauge, R. H.; Tour, J. M.; Smalley, R. E. Science 2003, 301, 1519. (k) Kamaras, K.; Itkis, M. E.; Hu, H.; Zhao, B.; Haddon, R. C. Science 2003, 301, 1501. (1) Chen, Z.; Du, X.; Du, M.; Rancken, C. D.; Cheng, H.; Rinzler, A. G. Nano Lett. 2003, 3, 
1245. (m) Yudasaka, M.; Zhang, M.; Iijima, S. Chem. Phys. Lett. 2003, 374, 132. (n) Arnold, M. S.; Green, A. A.; Hulvat, J. F.; Stupp, S. I.; Hersam, M. C. Nat. Nanotech. 2006, 1, 60.

(11) (a) Collins, P.; Arnold, M.; Avouris, P. Science 2001, 292, 706. (b) Seidel, R.; Graham, A. P.; Unger, E.; Duesberg, G. S.; Liebau, M.; Steinhoegl, W.; Kreupl, F.; Hoenlein, W.; Pompe, W. Nano Lett. 2004, 4, 831. (c) Fukao, T.; Nakamura, S.; Kataura, H.; Shiraishi, M. Jpn. J. Appl. Phys., Part 1 2006, 45, 6524. (d) Zhou, Y.; Gaur, A.; Hur, S.-H.; Kocabas, C.; Meitl, M. A.; Shim, M.; Rogers, J. A. Nano Lett. 2004, 4, 2031.

(12) (a) An, L.; Fu, Q.; Lu, C.; Liu, J. J. Am. Chem. Soc. 2004, 126, 10520. (b) Balasubramanian, K.; Sordan, R.; Burghard, M.; Kern, K. Nano Lett. 2004, 4, 827.

(13) Huang, H.; Maruyama, R.; Noda, K.; Kajiura, H.; Kadono, K. J. Phys. Chem. B 2006, 110, 7316 .

(14) (a) Hassanien, A. Nanotechnology 2005, 16, 278. (b) Zhang, G. Y.; Qi, P. F.; Wang, X. R.; Lu, Y. R.; Li, X. L.; Tu, R.; Bangsaruntip, S.; Mann, D.; Zhang, L.; Dai, H. J. Science 2006, 314, 974. (c) Chen, B. H.; Wei, J. H.; Lo, P. Y.; Pei, Z. W.; Chao, T. S.; Lin, H. C.; Huang, T. Y. Jpn. J. Appl. Phvs., Part 1 2006, 45, 3680.

(15) Rotkin S. V.; Subramoney S. Applied Physics of Carbon Nanotubes: Fundamentals of Theory, Optics and Transport Devices; Springer: Berlin, August 2005.

(16) (a) Li, Y. M.; Mann, D.; Rolandi, M.; Kim, W.; Ural, A.; Hung, S.; Javey, A.; Cao, J.; Wang, D.; Yenilmez, E.; Wang, Q.; Gibbons, J. F.; Nishi, Y.; Dai, H. Nano Lett. 2004, 4, 317. (b) Li, Y.; Peng, S.; Mann, D.; Cao, J.; Tu, R.; Cho, K. J.; Dai, H. J. Phys. Chem. B 2005, 109, 6968.

(17) Bachilo, S. M.; Balzano, L.; Herrera, J. E.; Pompeo, F.; Resasco, D. E.; Weisman, R. B. J. Am. Chem. Soc. 2003, 125, 11186.

(18) Li, X.; Tu, X.; Zaric, S.; Welsher, K.; Seo, W. S.; Zhao, W.; Dai, H. J. Am. Chem. Soc. 2007, 129, 15770.

(19) Wang, B.; Patrick Poa, C. H.; Wei, L.; Li, L. J.; Yang, Y. H.; Chen, Y. J. Am. Chem. Soc. 2007, 129, 9014.

(20) Miyauchi, Y.; Chiashi, S.; Murakami, Y.; Hayashida, Y.; Maruyama, S. Chem. Phvs. Lett. 2004, 387, 198.

(21) Ciuparu, D.; Chen, Y.; Lim, S.; Haller, G. L.; Pfefferle, L. J. Phvs. Chem. B 2004, 108, 503.

(22) Lee, K. M.; Li, L.; Dai, L. J. Am. Chem. Soc. 2005, 127, 4122.

(23) Qu, L. T.; Dai, L. M. Chem. Commun. 2007, 37, 3859.

(24) See, for examples: (a) Wei, B. Q.; Vajtai, R.; Jung, Y.; Ward, J.; Zhang, R.; Ramanath, G.; Ajayan, P. M. Nature 2002, 416, 495. (b) Li, W. Z.; Xie, S. S.; Qian, L. X.; Chang, B. H.; Zou, B. S.; Zhou, W. Y.; Zhao, R. A.; Wang, G. Science 1996, 274, 1701. (c) Fan, S.; Chapline, M. G.; Franklin, N. R.; Tomber, T. W.; Cassell, A. M.; Dai, H. Science 1999,
283, 512. (d) Ren, Z. F.; Huang, Z. P.; Xu, J. H.; Wang, P. B.; Siegal, M. P.; Provencio, P. N. Science 1998, 282, 1105. (e) Dai, L.; Patil, A.; Gong, X. Y.; Guo, Z. X.; Liu, L.Q.; Liu, Y.; Zhu, D. B. ChemPhysChem 2003, 4, 1150. (f) Qu, L. T.; Zhao, Y.; Dai, L. Small 2006, 2, 1052.

(25) See, for examples: (a) Hata, K.; Futaba, D. N.; Mizuno, K.; Namai, T.; Yumura, M.; Iijima, S. Science 2004, 306, 1362. (b) Zhang, G.; Mann, D.; Zhang, L.; Javey, A.; Li, Y.; Yenilmez, E.; Wang, Q.; McVittie, J. P.; Nishi, Y.; Gibbons, J.; Dai, H. Proc. Natl. Acad. Sci. U.S.A. 2005, 102, 16141. (c) Gyula, E.; Kinkhabwala, A. A.; Cui, H.; Geohegan, D. B.; Puretzky, A. A.; Lowndes, D. H. J. Phys. Chem. B 2005, 109, 16684. (d) Iwasaki, T.; Zhong, G. F.; Aikawa, T.; Yoshida, T.; Kawarada, H. J. Phys. Chem. B 2005, 109, 19556. (e) Xu, Y. Q.; Flor, E.; Kim, M. J.; Hamadani, B.; Schmidt, H.; Smalley, R. E.; Hauge, R. H. J. Am. Chem. Soc. 2006, 128, 6560. (f) Cantoro, M.; Hofmann, S.; Pisana, S.; Scardaci, V.; Parvez, A.; Ducati, C.; Ferrari, A. C.; Blackburn, A. M.; Wang, K. Y.; Robertson, J. Nano Lett. 2006, 6, 1107. (g) Murakami, Y.; Chiashi, S.; Miyauchi, Y.; Hu, M. H.; Ogura, M.; Okubo, T.; Maruyama, S. Chem. Phys. Lett. 2004, 385, 298. (h) Zhang, L.; Tan, Y. Q.; Resasco, D. E. Chem. Phys. Lett. 2006, 422, 198.

(26) Qu, L. T.; Dai, L. M. Adv. Mater. 2007, 19, 3844.

(27) Qu, L. T.; Dai, L. M. J. Mater. Chem. 2007, 17, 3401.

(28) (a) Strano, M. S.; Doorn, S. K.; Haroz, E. H.; Kittrell, C.; Hauge, R. H.; Smalley, R. E. Nano Lett. 2003, 3, 1091. (b) Bachilo, S. M.; Strano, M. S.; Kittrell, C.; Hauge, R. H.; Smalley, R. E.; Weisman, R. B. Science 2002, 298, 2361. (c) Samsonidze, G. G.; Chou, S. G.; Santos, A. P.; Brar, V. W.; Dresselhaus, G.; Dresselhaus, M. S.; Selbst, A.; Swan, A. K.; Unlu, M. S.; Goldberg, B. B.; Chattopadhyay, D.; Kim, S. N.; Papadimitrakopoulos, F. Appl. Phys. Lett. 2004, 85, 1006.

(29) Di Donato, E.; Tommasini, M.; Castiglioni, C.; Zerbi, G. Phys. Rev. B 2006, 74, 184306.

(30) Tan, P. H.; Rozhin, A. G.; Hasan, T.; Hu, P.; Scardaci, V.; Milne, W. I.; Ferrari, A. C. Phys. Rev. Lett. 2007, 99, 137402.

(31) Shiraishi, M.; Takenobu, T.; Iwai, T.; Iwasa, Y.; Kataura, H.; Ata, M. Chem. Phys. Lett. 2004, 394, 110.

(32) (a) Kumar, S.; Pimparkar, N.; Murthy, J. Y.; Alam, M. A. Appl. Phys. Lett. 2006, 88, 123505. (b) Snow, E. S.; Novak, J. P.; Campbell, P. M.; Park, D. Appl. Phys. Lett. 2003, 82, 2145. (c) Li, J.; Zhang, Z. B.; Östling, M.; Zhang, S. L. Appl. Phvs. Lett. 2008, 92, 133103. (d) Javey, A.; Guo, J.; Paulsson, M.; Wang, Q.; Mann, D.; Lundstrom, M.; Dai, H. Phys. Rev. Lett. 2004, 92, 106804.

NL800967N 